\title{
Predictors and ICU outcomes of neurogenic pulmonary edema in aneurysmal subarachnoid hemorrhage.
}

\author{
MEBAOUJ S., PANIGOT N., DHIF N., STOJEBA N., PAIN L.
}

Nouvel Hopital Civil, Dept of Anaesthesiology \& Intensive Care, Strasbourg, France, University Hospital Strasbourg, Dept of Anaesthesiology \& Intensive Care, Strasbourg,

France.

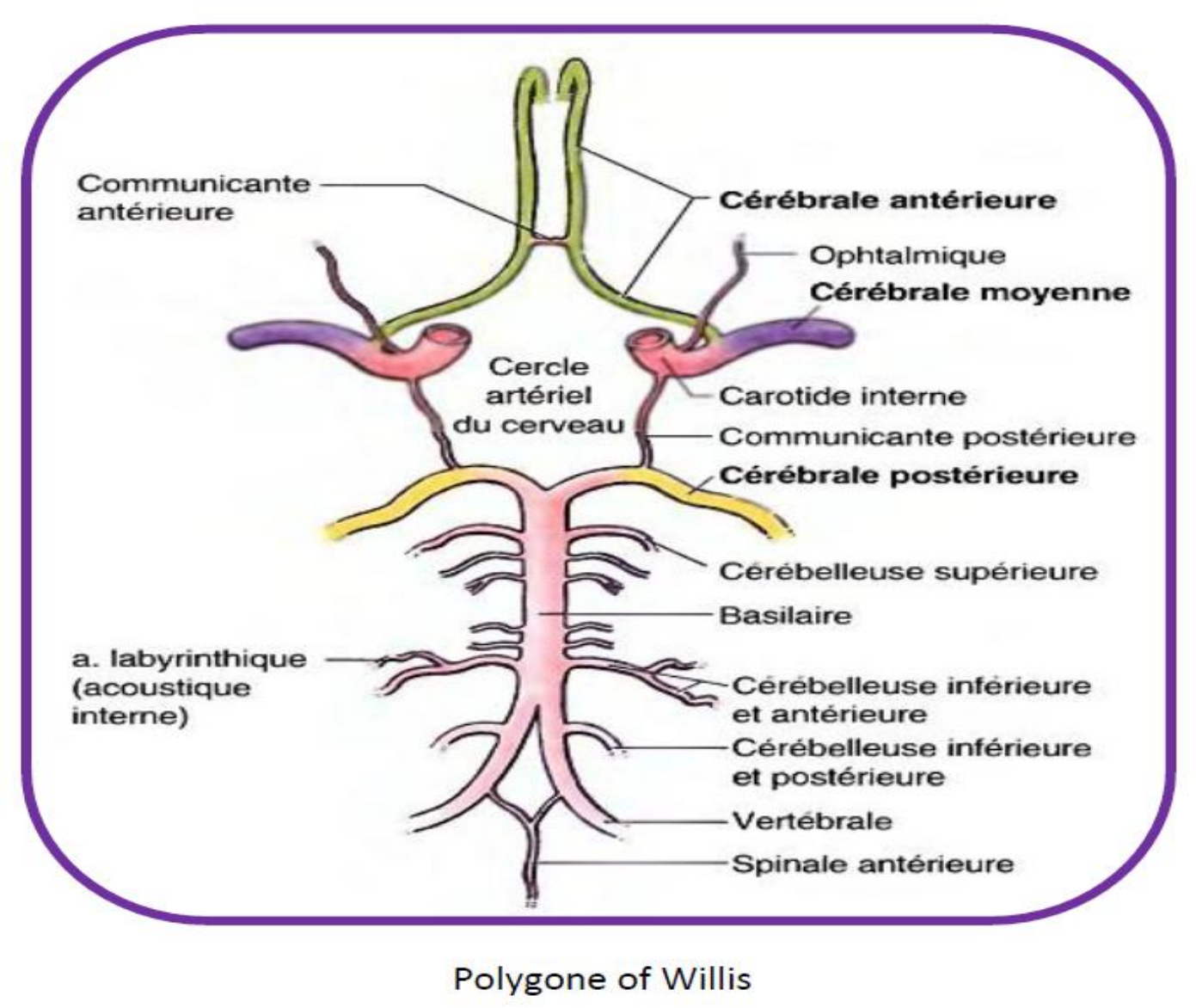

Background and goal of study: Aneurysmal subarachnoid hemorrhage (ASH) could be complicated with neurogenic pulmonary edema (NPE). The incidence of this pathology is between 2 and $20 \%$ in an acute pathology of the central nervous system. NPE post ASH occurs most often between $\mathrm{J} 0$ and $\mathrm{J} 7$, concomitantly with initial cerebral (hemorrhage) or secondary (vasospasm, ischemia). For years, a poor grade ASH was considered as the main factor the occurrence of NPE. However, the location of aneurysm (posterior circulation) has been proposed as predictive of NPE with no role for patient factors or clinical features of ASH. The objectives were to determine predictive factors for the occurrence of early NPE in patients with ASH and outcomes of patients with or without NPE in intensive care unit (ICU) . Materials and methods:We carried out a retrospective and monocentric descriptive observational study at the University Hospital Center in Strasbourg between 2010 and 2014. We analyzed records of patients who were admitted at University Hospital for ASH during a 5 years period. In Strasbourg, patients are systematically admitted to the ICU for the management of subarachnoid hemorrhage linked to a ruptured aneurysm documented by a cerebral scan. The data studied in the patients included are respectively: demography (age, sex, incidence of body mass) and medical history clinical features of ASH, aneurysm characteristics, ICU parameters at Day 2 and Day 7 and ICU outcomes. Diagnostic of NPE was set up by clinical and preclinical criteria (transthoracic heart ultrasound, electrocardiogram, type B natriuretic peptide, troponin, $\mathrm{PaO} 2$ / $\mathrm{FiO} 2$ ratio). Thus, in order to determine the possible risk factors for the occurrence of neurogenic pulmonary edema (presence or absence), a logistic regression analysis made it possible to retain the incriminated factors (alpha <0.05) for the multivariate analysis. A multivariable logistic regression model included all independent variables with $\mathrm{P}<0.25$ in the univariate analysis.

Results and discussion: Cases files of 193 patients were analyzed; NPE observed in 17 patients.8.8\% of patients had a NPE (16 female/1 male, average age 58 years). The type $\mathrm{B}$ natriuretic peptide and troponin levels (average, STDEV) were 1504 (131) and 8.07 (1.76) respectively. In the group with NPE, Left Venticular Ejection Fraction was $31.25 \%$ associated with dilation of the left ventricular in $17.6 \%$ of cases and alteration of segmental kinetics in $47 \%$ of cases. On stepwise

\begin{tabular}{|c|c|c|c|c|c|}
\hline & \multicolumn{2}{|c|}{$\begin{array}{l}\text { Neurogenic pulmonary } \\
\text { edema }(n=17)\end{array}$} & \multicolumn{2}{|c|}{$\begin{array}{l}\text { No neurogenic pulmonary } \\
\text { edema }(n=176)\end{array}$} & $\begin{array}{l}\text { Valeur } \\
\text { de P }\end{array}$ \\
\hline $\begin{array}{c}\mathrm{PaO} 2 / \mathrm{FiO} 2 \mathrm{J2} \\
\text { (average, STDEV) }\end{array}$ & \multicolumn{2}{|c|}{$270(11)$} & \multicolumn{2}{|c|}{$306(30)$} & NS \\
\hline $\begin{array}{c}\text { PaO2/FiO2 J7 } \\
\text { (average, STDEV) }\end{array}$ & \multicolumn{2}{|r|}{$267(13)$} & \multicolumn{2}{|r|}{$236(39)$} & NS \\
\hline VasospasmJ2 (n, \%) & \multicolumn{2}{|r|}{$4(23,5 \%)$} & \multicolumn{2}{|r|}{$25(14,2 \%)$} & NS \\
\hline Vasospasm J7 (n, \%) & \multicolumn{2}{|r|}{$3(17,65 \%)$} & \multicolumn{2}{|r|}{$23(13 \%)$} & NS \\
\hline Natremia J2 & \multicolumn{2}{|r|}{$142(32)$} & \multicolumn{2}{|r|}{$142(21)$} & NS \\
\hline Natremia J7 & \multicolumn{2}{|r|}{ 139(39) } & \multicolumn{2}{|r|}{$139(22)$} & NS \\
\hline & \multicolumn{3}{|c|}{$\begin{array}{c}\text { Neurogenic pulmonary } \\
\text { edema }(n=17)\end{array}$} & \multicolumn{2}{|c|}{$\begin{array}{c}\text { No neurogenic pulmonary } \\
\text { edema }(n=176)\end{array}$} \\
\hline \multicolumn{2}{|l|}{ Death $(n, \%)$} & \multicolumn{2}{|c|}{$6(35,3 \%)$} & \multicolumn{2}{|c|}{$37(21 \%)$} \\
\hline \multicolumn{2}{|c|}{$\begin{array}{c}\text { Length of stay, in days } \\
\text { (average,STDEV) }\end{array}$} & \multicolumn{2}{|c|}{$15,4(20,3)$} & \multicolumn{2}{|l|}{$11,4(11,2)$} \\
\hline \multicolumn{6}{|c|}{$\begin{array}{c}\text { Glasgow score at the exit of } \\
\operatorname{ICU}(n, \%)\end{array}$} \\
\hline \multicolumn{2}{|c|}{ Glasgow 15} & \multirow{2}{*}{\multicolumn{2}{|c|}{$\frac{7}{3}$}} & \multicolumn{2}{|l|}{102} \\
\hline \multirow{2}{*}{\multicolumn{2}{|c|}{$\begin{array}{l}\text { Glasgow 13-14 } \\
\text { Glasgow 10-12 }\end{array}$}} & & & 26 & \\
\hline & & \multicolumn{2}{|l|}{0} & \multicolumn{2}{|l|}{4} \\
\hline \multicolumn{2}{|l|}{ Glasgow 7-9 } & \multirow{2}{*}{\multicolumn{2}{|c|}{$\begin{array}{l}0 \\
1\end{array}$}} & \multicolumn{2}{|l|}{3} \\
\hline \multicolumn{2}{|l|}{ Glasgow 3-6 } & & & \multicolumn{2}{|l|}{4} \\
\hline
\end{tabular}

logistic regression, sex, hypertension, vascular pathology, WFNS grade, aneurysm location (grouped as anterior or posterior; posterior location defined as any aneurysm of the vertebral or basilar segment) were found to be relevant factors. On multivariate logistic regression modeling, the occurrence of NPE, sex, hypertension, vascular pathology, aneurysm locations were found to be independent predictors. We identified five risk factors for NPE (posterior aneurysm, vascular risk factor, female sex, arterial hypertension, posterior aneurysm and WFNS(III, IV,V).

\begin{tabular}{|c|c|c|}
\hline Source & Log Worth $(-\log 10)$ & P Value \\
\hline Aneurysm location (posterior) & 3,920 & 0,00012 \\
\hline Vascular pathology (presence) & 2,784 & 0,00164 \\
\hline Sex (female) & 2,659 & 0,00220 \\
\hline Arterial hypertension (presence) & 1,638 & 0,02302 \\
\hline Aneurysm location (posterior) xWFNS (III,IV,V) & 1,319 & 0,04794 \\
\hline WFNS (III,IV,V) & 0,411 & 0,38809 \\
\hline
\end{tabular}

Comparing the two groups of patients with or without NPE, we did not observe any statistical differences in terms of mortality, length of stay and neurological status at discharge from ICU. In addition, no statistical differences were observed as regards to natremia, or presence of vasopasm and $\mathrm{PaO} 2$ / $\mathrm{FiO} 2$ ratio.

Conclusion(s): In our series of patients, an incidence of clinical NPE of $8.8 \%$ was observed. For patients with ruptured aneurysm, both patient specified factors (female, vascular pathology) an aneurysm specified factors (posterior location, particularly with bad neurological status) need to be carefully considered as high risk factors of developing NPE. 